\title{
SASKATCHEWAN EVERGREENS
}

\section{Stuart Francis.}

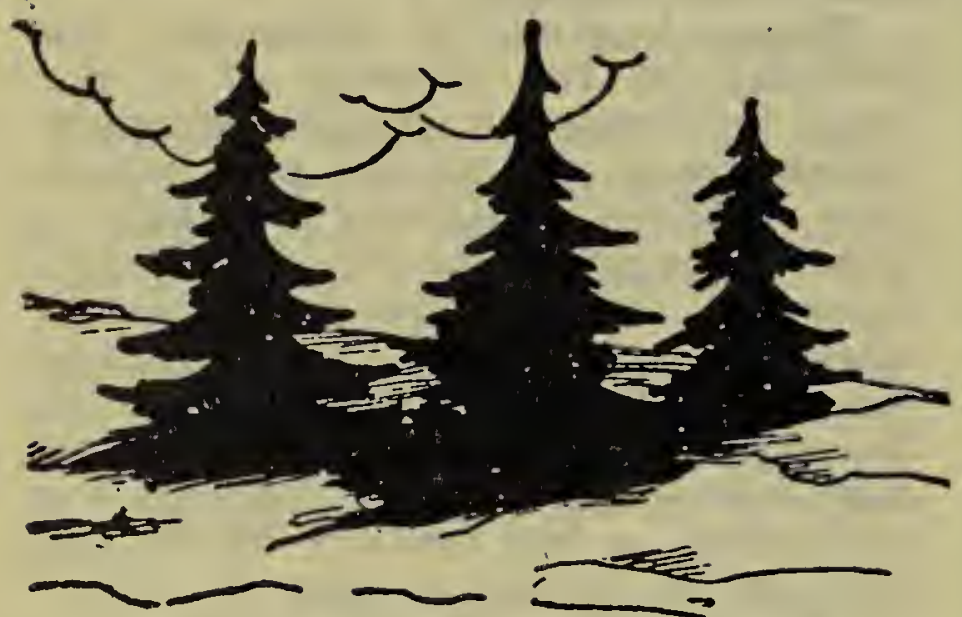

Saskatchewan is often referred to as a prairie province. Actually, however, I believe that our province contains more square miles of forest and parkland than open prairie. In the frontier regions of northern Saskatchewan the density and variety of forest growth has to be seen to be understood.

WHITE SPRUCE sometimes grows to a height of 100 to 110 or more feet, and in diameter to a girth of 3 to 4 feet, and one single tree will contain a thousand feet of lumber or more.

JACKPINE also grows to a considerable size on certain soils and often attains a height of 75 to 80 feet. One Jackpine that grows within a mile of my house has a circumference of 8 feet 10 inches, at one foot above the ground. This particular Jackpine is, so far as I have been able to ascertain, the largest pine so far noted in the province.

BALSAM FIR is another evergreen tree native to Saskatchewan, and closely resembles the spruce at a short distance. It is a really beautiful tree, with flat, shiny, dark green needles and is very aromatic, both in the branches and also in the bark when cut into or broken. The bark of the Balsam Fir is usually much smoother than the bark of either spruce or pine and reflects light to a certain extent, giving it a shiny appearance. This tree also grows to considerable size on certain river bottom locations and most favored soils. I have seen Balsam Fir which reached a height of 80 feet or more, with a diameter of 2 feet or more.
The seed cones of Balsam Fir, unlike the seed cones of spruce or pine which hold their form until they rot away with age, disintrigrate just as soon as the seed is ripe. Then the seed and cone fragments scatter about in the wind.

BLACK SPRUCE is another form of evergreen tree native to Saskatchewan. It is quite different from White Spruce in that it has much shorter needles than any of the other native evergreens. The needles as well as being shorter and much bluer in color, are formed on branches which hang downward and outward and are more curved than White Spruce. The seed cones are very small and round and grow in dense clusters close to the trunis of the tree. They are sometimes attached directly to the tree trunk. The tree usually grows very symmetrical in shape, but does not grow as large as White Spruce or Jackpine. Sometimes, however, it attains a height of from 75 to 80 feet and with a diameter of from 16 to 18 inches.

\section{They Stimulate The Imagination}

I By Chas. Stewart, Saskatoon

PARTICULARLY enjoyed the article, "Influence of Material on Indian Stone Culture," by Mr. Allan $\mathrm{J}$ : Hudson, and am looking forward to reading further articles by him. I am much interested in the Indian artifacts of Western Canada.

It was students such as Mr. Hudson and others interested in similar work that Elbert Hubbard had in mind when he wrote; "We are brothers not only to all who live, but to all who have gone before. And so we collect the trifles for other men, and by the possession of these trifles are we bounden to them. These things stimulate imagination, stir the sympathies and help us forget the cramping bounds of time and space that so often hedge us close around." 